\title{
Heteroexpression and Functional Characterization of Glucose 6-Phosphate Dehydrogenase from Industrial Aspergillus oryzae ${ }^{\mathbb{5}}$
}

\author{
Hongwei Guo, Jinyao Han, Jingjing Wu, and Hongwen Chen* \\ School of Chemical Engineering, Huaqiao University, Xiamen 361021, P.R. China
}

\author{
Received: December 30, 2018 \\ Revised: January 25, 2019 \\ Accepted: January 29, 2019 \\ First published online \\ February 8, 2019 \\ *Corresponding author \\ Phone: +86-592-6162347; \\ E-mail: chenhw@hqu.edu.cn \\ S upplementary data for this \\ paper are available on-line only at \\ http://jmb.or.kr. \\ pISSN 1017-7825, eISSN 1738-8872 \\ Copyright(C) 2019 by \\ The Korean Society for Microbiology \\ and Biotechnology
}

The engineered Aspergillus oryzae has a high NADPH demand for xylose utilization and overproduction of target metabolites. Glucose-6-phosphate dehydrogenase (G6PDH, E.C. 1.1.1.49) is one of two key enzymes in the oxidative part of the pentose phosphate pathway, and is also the main enzyme involved in NADPH regeneration. The open reading frame and cDNA of the putative A. oryzae G6PDH (AoG6PDH) were obtained, followed by heterogeneous expression in Escherichia coli and purification as a his6-tagged protein. The purified protein was characterized to be in possession of G6PDH activity with a molecular mass of $118.0 \mathrm{kDa}$. The enzyme displayed maximal activity at $\mathrm{pH} 7.5$ and the optimal temperature was $50^{\circ} \mathrm{C}$. This enzyme also had a half-life of $33.3 \mathrm{~min}$ at $40^{\circ} \mathrm{C}$. Kinetics assay showed that AoG6PDH was strictly dependent on $\operatorname{NADP}^{+}\left(K_{\mathrm{m}}=6.3 \mu \mathrm{M}, k_{\text {cat }}=1000.0 \mathrm{~s}^{-1}, k_{\text {cat }} / K_{\mathrm{m}}=158.7 \mathrm{~s}^{-1} \cdot \mu \mathrm{M}^{-1}\right)$ as cofactor. The $K_{\mathrm{m}}$ and $k_{\text {cat }} / K_{\mathrm{m}}$ values of glucose-6-phosphate were $109.7 \mathrm{~s}^{-1} \cdot \mu \mathrm{M}^{-1}$ and $9.1 \mathrm{~s}^{-1} \cdot \mu \mathrm{M}^{-1}$ respectively. Initial velocity and product inhibition analyses indicated the catalytic reaction followed a two-substrate, steady-state, ordered BiBi mechanism, where $\mathrm{NADP}^{+}$was the first substrate bound to the enzyme and NADPH was the second product released from the catalytic complex. The established kinetic model could be applied in further regulation of the pentose phosphate pathway and NADPH regeneration of A. oryzae to improve its xylose utilization and yields of valued metabolites.

Keywords: Pentose phosphate pathway, glucose-6-phosphate dehydrogenase, xylose, Aspergillus oryzae, ordered Bi-Bi mechanism

\section{Introduction}

Applying consolidated bioprocessing (CBP) technology is one of the most cost-effective routes for producing biofuels and chemicals, including ethanol, butanol and xylitol, directly from renewable biomass [1]. Aspergillus oryzae, as a Generally Recognized as Safe microbe, has been widely utilized in traditional food processing for centuries [2]. Known for its secretion of ligninolytic and hydrolytic enzymes [3], this filamentous fungus strain has been used to produce biodiesel, lipids and enzymes directly from lignocellulosic feed stocks [4-6]. The hydrolysates of the lignocellulose contain a mixture of glucose and xylose, [7] although the poor utilization of xylose remains the dominant hurdle to overcome with this organism [8].

In $A$. oryzae, the utilization of xylose is via three enzyme reactions involving xylose reductase, xylitol dehydrogenase and xylulokinase, to form xylulose 5-phophate, which enters the pentose phosphate pathway (PP pathway) (Fig. 1) [9]. Among these enzyme reactions, the metabolic flux of xylose metabolism has been tightly regulated by the activity of NADPH-dependent xylose reductase [10]. Metabolic strategies to enhance cofactor supply and regeneration have been extensively applied for improving xylose utilization and desired metabolite production in E. coli, Candida tropicalis and Saccharomyces cerevisiae [1113]. Whereas, cofactor engineering strategies were seldom reported in A. oryzae for improving xylose utilization; even genes contributing to cofactor catabolism and biosynthesis were not well studied.

In many species, the main source of NADPH and its generation is the oxidative part of the PP pathway. 


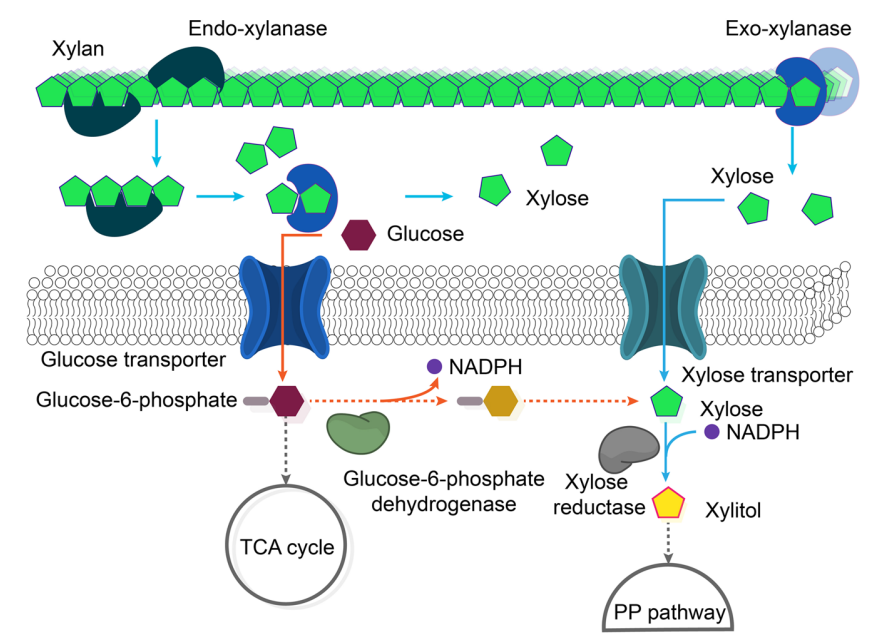

Fig. 1. Production of xylitol in A. oryzae from xylan.

Glucose-6-phosphate dehydrogenase (gsd, G6PDH, E.C. 1.1.1.49) is the first enzyme in the PP pathway and converts glucose-6-phosphate (G6P) to 6-phosphate-gluconolactone with concomitant generating of NADPH or NADH. In eukaryotic cells, the expression level of G6PDH is relatively constant $[14,15]$ and it was also reported that the catalysis of G6PDH was the rate-limiting catalytic step of the PP pathway [14, 16]. Accordingly, the potential for improving xylose utilization by regulation of G6PDH activity is high. However, in the genome database of A. oryzae, the open reading frame (ORF) of $g s d$ is annotated as a tentative G6PDH. Gene verification and functional characterization of G6PDH from industrial A. oryzae (AoG6PDH) were also lacking.

The successful cloning and expression of the $g s d$ and the characterization of the purified recombinant G6PDH from A. oryzae CICC2012 are only being reported here for the first time. The two-substrate, steady-state kinetic analysis, in addition to product and substrate inhibition studies, have also been established. This study provides essential clues into further regulation of the NADPH regeneration of A. oryzae to improve its production of the valued metabolites.

\section{Materials and Methods}

\section{Strains and Culture Conditions}

Glucose peptone (GP) medium containing $20 \mathrm{~g} / 1$ glucose, $10 \mathrm{~g} / 1$ peptone, $5 \mathrm{~g} / 1 \mathrm{KH}_{2} \mathrm{PO}_{4}, 1 \mathrm{~g} / 1 \mathrm{NaNO}_{3}, 1 \mathrm{~g} / 1 \mathrm{MgSO}_{4} \cdot 7 \mathrm{H}_{2} \mathrm{O}$ was used for cultivating A. oryzae CICC2012 (China Industrial Microbiological Culture Collection Center) in a 250-ml shaker flask (150 rpm) for 3 days at $30^{\circ} \mathrm{C}, \mathrm{pH}$ 6.0. LB medium supplemented with ampicillin $(100 \mu \mathrm{g} / \mathrm{ml})$ was used for cultivating E. coli strains at $37^{\circ} \mathrm{C}$. The
E. coli DH5 $\alpha$ was used for plasmid propagation and E. coli BL21 (DE3) was used for protein heterogeneous expression. Super Optimal broth with Catabolite repression (SOC) medium containing $20 \mathrm{~g} / 1$ tryptone, $5 \mathrm{~g} / 1$ yeast extract, $5 \mathrm{~g} / 1 \mathrm{NaCl}, 2.5 \mathrm{mM} \mathrm{KCl}$, $10 \mathrm{mM} \mathrm{MgCl} 2,20 \mathrm{mM}$ glucose was used to transform plasmid into competent cells at $37^{\circ} \mathrm{C}$ and $\mathrm{pH} 7.0$, and this was followed by spreading in $\mathrm{LB}$ plates for $12 \mathrm{~h}$ at $37^{\circ} \mathrm{C}$. And $\mathrm{TB}$ medium containing $12 \mathrm{~g} / 1$ peptone, $24 \mathrm{~g} / 1$ yeast extract, $2.3 \mathrm{~g} / 1 \mathrm{KH}_{2} \mathrm{PO}_{4}$, $16.4 \mathrm{~g} / 1 \mathrm{~K}_{2} \mathrm{HPO}_{4}, 5 \mathrm{~g} / \mathrm{l}$ glycerol and isopropyl $\beta$-D-thiogalactoside (IPTG) was used for the induced expression of proteins.

\section{Chemicals and Plasmids}

Plasmid pUC19T-vector (pUCm-T), pET-28a(+), Taq DNA polymerase, RNase A, dNTP, DNA Gel Extraction Kit and EZ Column Plasmid Mini-Preps Kit were purchased from Sangon (China). Ligation reagents, restriction endonucleases and DNA marker were purchased from TaKaRa (China).

\section{Obtaining of ORF and CDS of $g s d$}

Genomic DNA of $A$. oryzae was prepared using a previously described method [17]. The G6PDH coding gene gsd was amplified from $A$. oryzae genomic DNA using the primers P1/P2 designed from the putative $g s d$ from $A$. oryzae RIB40 (Dogan AO 090005001427) (Table S1). PCR product was purified and cloned into pUC19T vector to obtain the cloning plasmid pUC19-gsdDNA, which was followed by sequencing conducted by Invitrogen (China).

\section{Bioinformatic Analysis}

The $g s d$ and corresponding cDNA sequences were deduced with the putative G6PDH from A. oryzae RIB40 (NCBI reference sequence: XP_001818354.2) as a reference sequence using the DNAMAN program. The protein modelling was constructed using SWISS-MODEL [18] and multiple sequence alignment was performed using CLUSTALW 2.1.

\section{Heterogeneous Expression and Purification of G6PDH}

To eliminate the effects of intron from A. oryzae CICC2012 on heterogeneous expression in the cells of E. coli, the cDNA of A. oryzae CICC2012 was reverse transcribed and synthesized from general RNA of the fungi cell. The synthesized cDNA was used as PCR template subsequently. PCR gene specific primers for A. oryzae CICC2012 gsd were designed from the putative G6PDH from A. oryzae RIB40 (NCBI reference sequence: XP_001818354.2). The putative gsd was amplified by two-step fusion PCR, using three pairs of oligonucleotide primers (Table S1). Primers 1F/1R and $2 \mathrm{~F} / 2 \mathrm{R}$ were used to amplify $g s d-\mathrm{F} 1$ and $g s d-\mathrm{F} 2$ respectively, and primers $3 \mathrm{~F} / 3 \mathrm{R}$ were utilized to fuse the $g s d-\mathrm{F} 1$ and $g s d-\mathrm{F} 2$ to the complete sequence. The fusion PCR product was purified, and subsequently cloned into pUC19 vector (Sangon, China) to construct the recombined plasmid pUC19-gsd-cDNA, which was followed by sequencing. pUC19-gsd-cDNA was extracted by Spin Column Plasmid Mini-Preps Kit (Sangon), and was digested by 
Bam $\mathrm{HI}$ and Not I. The digestion production was cloned into the pET-28a $(+)$ vector (Novagen, USA) to generate the recombinant plasmid pET-gsd-cDNA.

The recombinant plasmid pET- $g s d-c D N A$ was transformed into cells of E. coli BL21 (DE3) and transformants were selected from LB medium containing $100 \mu \mathrm{g} / \mathrm{ml}$ ampicillin, which resulted in recombinant strain E. coli BL21-gsd. The fresh colony of E.coli BL21-gsd grown in LB media was transferred into TB medium with $100 \mu \mathrm{g} / \mathrm{ml}$ ampicillin at $37^{\circ} \mathrm{C}$ for $2-3 \mathrm{~h}$. When cell density $\mathrm{OD}_{600}$ reached $0.6-0.8$, protein was induced by addition of $1 \mathrm{mM}$ IPTG at $25^{\circ} \mathrm{C}$ for $12 \mathrm{~h}$. To protect the soluble protein, $2 \mathrm{mM}$ DLDithiothreitol was added into $1 \mathrm{ml}$ suspension culture [19]. Cells were harvested and sonicated on ice which was followed by centrifugation at $12,000 \times g$ for $15 \mathrm{~min}$ at $4^{\circ} \mathrm{C}$. The supernatant was loaded onto a $\mathrm{Ni}^{2+}$-chelated $(5 \mathrm{ml}$ ) column (CW Bio, China), which was pre-equilibrated with buffer $\mathrm{A}(0.5 \mathrm{M} \mathrm{NaCl}$ and $10 \mathrm{mM}$ imidazole). Elution was performed with buffer B $(0.5 \mathrm{M} \mathrm{NaCl}$ and $500 \mathrm{mM}$ imidazole). The elution product was gel-filtrated with a Superdex 200 column $(1 \times 30 \mathrm{~cm})$, which was pre-equilibrated and eluted with buffer $\mathrm{C}(0.5 \mathrm{M} \mathrm{NaCl})$. SDS-PAGE was performed using $12 \%$ separating gel to assess the purity and molecular weight of the recombinant G6PDH. Protein concentrations were determined using Bradford's assay with bovine serum albumin as the protein standard [20].

\section{Enzyme Activity Assays}

The activity of G6PDH was determined using the methods described with modifications [21]. G6PDH activities were measured by monitoring NADPH formation at $340 \mathrm{~nm}$ and at $25^{\circ} \mathrm{C}$ on a spectrophotometer, equipped with a thermo-stated cuvette holder. $200 \mu \mathrm{l}$ of the standard assay solution containing $50 \mathrm{mM}$ Tris- $\mathrm{HCl}$ buffer (pH 7.5), $5 \mathrm{mM} \mathrm{MgCl}, 0.4 \mathrm{mM} \mathrm{NADP}^{+}$ and $10 \mathrm{mM}$ G6P was utilized. The reaction was initiated by adding an appropriate amount of enzyme and the initial velocity of the reaction were assayed for $60 \mathrm{~s}$. One unit of G6PDH activity is the amount of enzyme catalyzing the formation of $1 \mu \mathrm{mol}$ of $\mathrm{NADPH}$ per minute under the assay conditions. Specific enzyme activity $(\mathrm{U} / \mathrm{mg})$ is defined as units per $\mathrm{mg}$ of protein.

\section{Biochemical Characterization}

The optimal $\mathrm{pH}$ was determined at $25^{\circ} \mathrm{C}$ using $100 \mathrm{mM}$ $\mathrm{Na}_{2} \mathrm{HPO}_{4}$-citric acid buffer ( $\mathrm{pH}$ 5.0-6.0), $100 \mathrm{mM} \mathrm{Na} \mathrm{NPO}_{4}$ $\mathrm{NaH}_{2} \mathrm{PO}_{4}$ buffer ( $\mathrm{pH}$ 6.5-7.5) and $100 \mathrm{mM}$ Tris- $\mathrm{HCl}$ buffer for $\mathrm{pH}$ 8.0-9.0, respectively. Optimal temperature was measured from 20 to $60^{\circ} \mathrm{C}$ in $100 \mathrm{mM} \mathrm{Na} \mathrm{HPO}_{4}-\mathrm{NaH}_{2} \mathrm{PO}_{4}$ buffer ( $\mathrm{pH}$ 7.5). To investigate thermo stability, the $\mathrm{G} 6 \mathrm{PDH}$ was incubated at $40^{\circ} \mathrm{C}$, $45^{\circ} \mathrm{C}, 50^{\circ} \mathrm{C}$, and $55^{\circ} \mathrm{C}$ at different time intervals in $100 \mathrm{mM}$ $\mathrm{Na}_{2} \mathrm{HPO}_{4}-\mathrm{NaH}_{2} \mathrm{PO}_{4}$ buffer ( $\mathrm{pH}$ 7.5). The residual activity was assayed to determine the half-lives of G6PDH. To analyze the effects of various metal ions on the activity of G6PDH, $1 \mathrm{mM}$ (final concentrations) of $\mathrm{Fe}^{2+}, \mathrm{Zn}^{2+}, \mathrm{Cu}^{2+}, \mathrm{Mg}^{2+}, \mathrm{Ba}^{2+}, \mathrm{Ca}^{2+}, \mathrm{K}^{+}$, and $\mathrm{Mn}^{2+}$ were added individually during the enzymatic activity assessment.

\section{Kinetics Study}

Substrate kinetics were determined at $25^{\circ} \mathrm{C}$ in $1 \mathrm{ml}$ reaction mixtures containing $50 \mathrm{mM}$ Tris- $\mathrm{HCl}$ buffer ( $\mathrm{pH}$ 7.5), $5 \mathrm{mM} \mathrm{MgCl}_{2}$ and various concentrations of G6P and $\mathrm{NADP}^{+}$. A matrix of substrate and coenzyme combinations between 100 500 $\mu \mathrm{M}$ G6P and 10 100 $\mu \mathrm{M} \mathrm{NADP}{ }^{+}$was performed and the reactions were initiated by the addition of enzyme. Catalytic inhibition of G6PDH by NADPH was performed by varying the concentrations of NADPH utilized in the reaction mixture. To assay the inhibition profile of $\mathrm{NADPH}$, one substrate with saturating concentrations $\left(10 \mathrm{mM} \mathrm{G} 6 \mathrm{P}\right.$ or $\left.0.40 \mathrm{mM} \mathrm{NADP}{ }^{+}\right)$and the other with unsaturated content were utilized in the mixture. The kinetic parameters were calculated by curve-fitting to the steady-state sequential kinetic equation 1 :

$$
\mathrm{V}=\frac{V_{\max }[A][B]}{K_{B}[A]+K_{A}[B]+K_{i A} K_{B}+[A][B]}
$$

Wherein $\mathrm{A}$ and $\mathrm{B}$ represent substrates $\mathrm{NADP}^{+}$and G6P, respectively. $V_{\max }$ is the maximum velocity and $\mathrm{K}_{\mathrm{iA}}$ is the dissociation constant of substrate $\mathrm{A}$ from the binary complex EA. $\mathrm{K}_{\mathrm{A}}$ and $\mathrm{K}_{\mathrm{B}}$ are the Michaelis constant $K_{\mathrm{m}}$ for substrates $\mathrm{A}$ and $\mathrm{B}$, respectively [22]. $K_{\mathrm{m}}$ and $V_{\max }$ were drawn from a two-round double reciprocal plot using Origin Pro 8.0 software (Origin Lab Corporation).

\section{Results}

\section{Cloning and Sequence Analysis of G6PDH in A. oryzae CICC2012}

As the genome sequence of $A$. oryzae CICC2012 has not been reported, the ORF of gsd from this fungus was deduced by utilizing the hypothesized G6PDH from A. oryzae RIB40. According to the putative G6PDH from A. oryzae RIB40 (Dogan AO 090005001427), primers P1/P2 were designed. The expected $2.8 \mathrm{~kb} g s d$ was amplified from A. oryzae CICC2012 genomic DNA using the primers P1/P2, and then cloned into pUC19T vector obtaining the plasmid pUC19-gsd-DNA. To eliminate intron, general RNA was extracted from $A$. oryzae CICC2012 mycelia and reversed transcribed into cDNA using a reverse transcriptase to synthesize cDNA. The synthesized cDNA was used as PCR template for the amplification of the gsd. As illustrated in Fig. S1, a putative $g s d$ with an expected size of $1.5 \mathrm{~kb}$ was obtained by a two-step fusion PCR reaction from cDNA, which was followed by cloning into pET-28a (+) to generate the expression plasmid pET-gsd-cDNA.

DNA sequencing of pUC19-gsd-DNA and pET-gsd-cDNA showed that the ORF and coding sequence (CDS) of $g s d$ of A. oryzae CICC2012 were totally identical to their counterparts from A. oryzae RIB40 hypothesized gsd respectively. The 
obtained cDNA of A. oryzae CICC2012 G6PDH was deposited in Genbank with accession number JN123468. The gsd ORF obtained from A. oryzae CICC2012 was $2,837 \mathrm{bp}$ including five introns. The six introns of $g s d$ were located at 1,033-1,199 bp, 1,305-1,357 bp, 1,442-1,500 bp, 1,581-1,634 bp, 1,841-1,893 bp, respectively. Meanwhile, the CDS was 1,533 bp encoding 510 amino acids with an estimated molecular weight of $58.8 \mathrm{kDa}$.

Multiple sequence alignment of the deduced amino acid sequence of G6PDH showed high similarity to its homologies from Aspergillus flavus (99\%) and Aspergillus niger $(97 \%)$, but less to S. cerevisiae (59\%). The similarity of different G6PDHs was consistent with the phylogenetic distance of different organisms (data not shown). A motif (RXXXEKPXG) in the coenzyme-binding site and three conserved motifs (annotation) (RIDHYLGK, EXXGXEXRXXY and DXXQNH) in the substrate-binding site were also observed in AoG6PDH (Fig. S2), indicating the G6P and $\mathrm{NADP}^{+}$binding and catalyzing residues were highly conserved [21]. The secondary structure of the protein was analyzed, the $\alpha$-helix region occupied $46.7 \%$, the $\beta$-sheet was $12.8 \%$ and the random coil was $40.6 \%$ (Fig. S3).

\section{Heterogenous Expression and Purification of AoG6PDH}

The recombinant strain E. coli BL21-gsd was obtained by transformation of expression plasmid pET-gsd-cDNA. Cellular lysate of E. coli BL21-gsd was subjected to SDSPAGE analysis (Fig. 2A), an over-expressed band with a size of around $55.0 \mathrm{kDa}$ was observed, in accordance with the expected value $58.8 \mathrm{kDa}$. A leaky expression profile

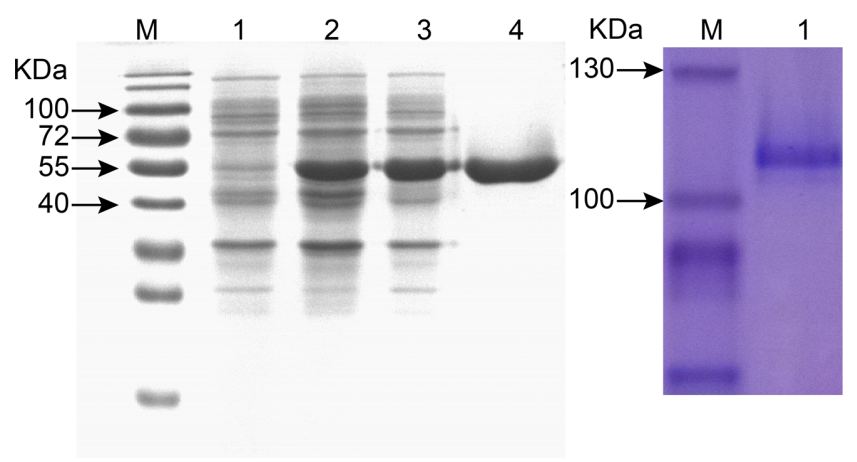

Fig. 2. Purification of heterogeneous expression of AoG6PDH. A: SDS-PAGE, Lane M: protein molecular mass marker; Lane 1: the lysate of E. coli BL21 (DE3); Lane 2: the lysate of E. coli BL21-gsd incubated without IPTG; Lane 3: the lysate of E. coli BL21-gsd incubated with IPTG; Lane 4: the purified AoG6PDH. B: NativePAGE, Lane M: protein molecular mass marker; Lane 1: the purified AoG6PDH. was also observed as the target protein band was obtained without IPTG. A $12.9 \mathrm{U} /(\mathrm{mg} \cdot$ protein) specific activity of
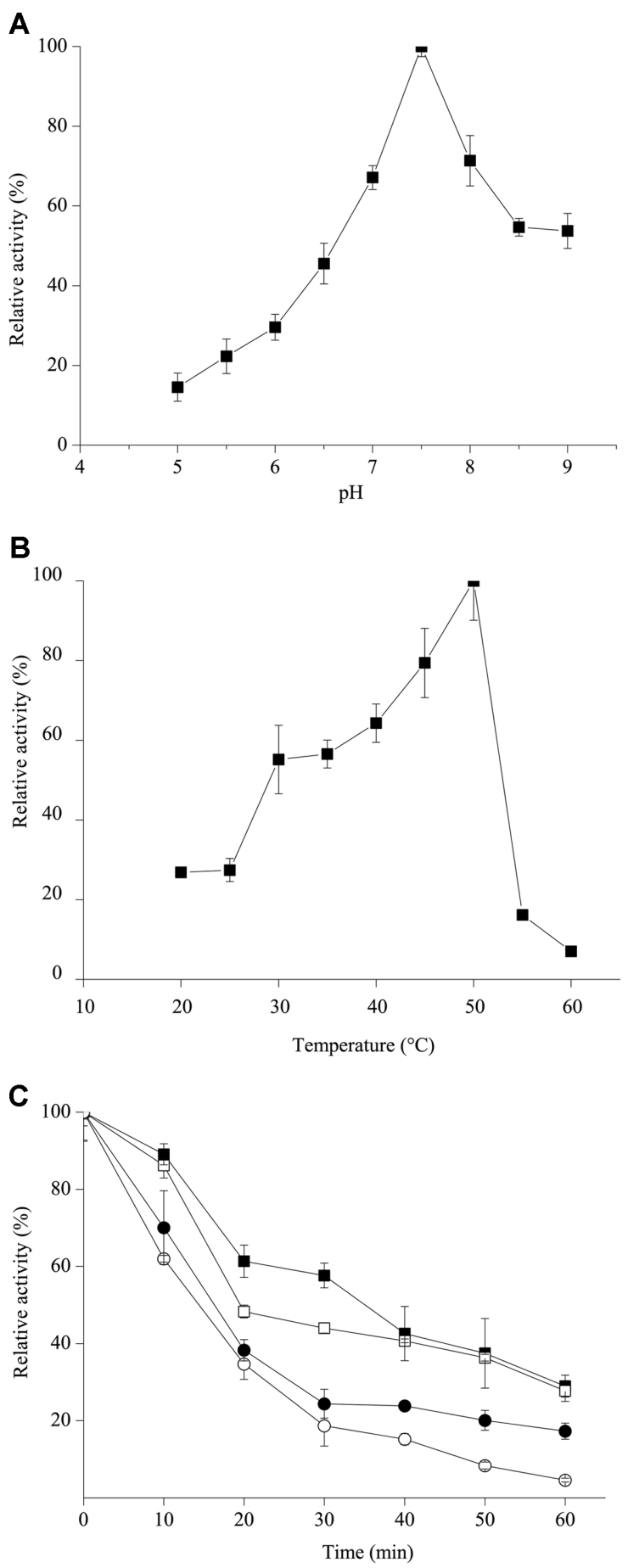

Fig. 3. The effects of $\mathrm{pH}(\mathbf{A})$ and temperature (B) on activity of recombinant AoG6PDH. The thermostability analysis of recombinant AoG6PDH $(\mathrm{C}), \mathbf{\square}: 40^{\circ} \mathrm{C}, \square: 45^{\circ} \mathrm{C}, \mathbf{O}: 50^{\circ} \mathrm{C}$, $\mathrm{O}: 55^{\circ} \mathrm{C}$ 
G6PDH was detected in the cellular lysate and then the recombinant G6PDH was purified to electrophoretic homogeneity by affinity chromatography (Fig. 2A). The specific activity of purified G6PDH was $73.6 \mathrm{U} /(\mathrm{mg} \cdot$ protein) with a recovery yield of $56.3 \%$ and 6.1 -fold purification. No enzyme activity was detected when $\mathrm{NAD}^{+}$was used as the coenzyme, as the purified G6PDH exhibited strictly $\mathrm{NADP}^{+}$-dependent specificity. The $\mathrm{NADP}^{+}$-dependent G6PDH of the purified product had high activity, which proved that the putative sequence was the encoding sequence of G6PDH.

Based on observation with Native-PAGE, AoG6PDH was a homodimer with an estimated molecular weight of $118.0 \mathrm{kDa}$ (Fig. 2B). The observation suggested that G6PDH was a homodimer, which was similar to G6PD from L. mesenteroides (dimer, LmG6PDH) [23] but different from sheep brain cortex G6PD (monomer) [24], Brugia malayi G6PD (tetramer) [25], human erythrocytes G6PD (switch between dimer and tetramer) [26] and rat liver G6PD (regularly forms hexamers) [16]. The protein modelling of AoG6PDH shown in Fig. S4 was constructed using SWISSMODEL, which coincided with the observation using Native-PAGE.

\section{Biochemical Characterization of AoG6PDH}

The effects of $\mathrm{pH}$ and temperature on G6PDH activity were examined in the presence of $\mathrm{G} 6 \mathrm{P}$ and $\mathrm{NADP}^{+}$, respectively. The optimal $\mathrm{pH}$ of $\mathrm{G} 6 \mathrm{PDH}$ was around 7.5 (Fig. 3A). About $70 \%$ of G6PDH activities remained at $\mathrm{pH}$ 7.0 and 8.0. The enzyme had a similar $\mathrm{pH}$ profile to that of the other G6PDHs (Table 2). The optimal temperature was around $50^{\circ} \mathrm{C}$ (Fig. 3B), which was similar to the known
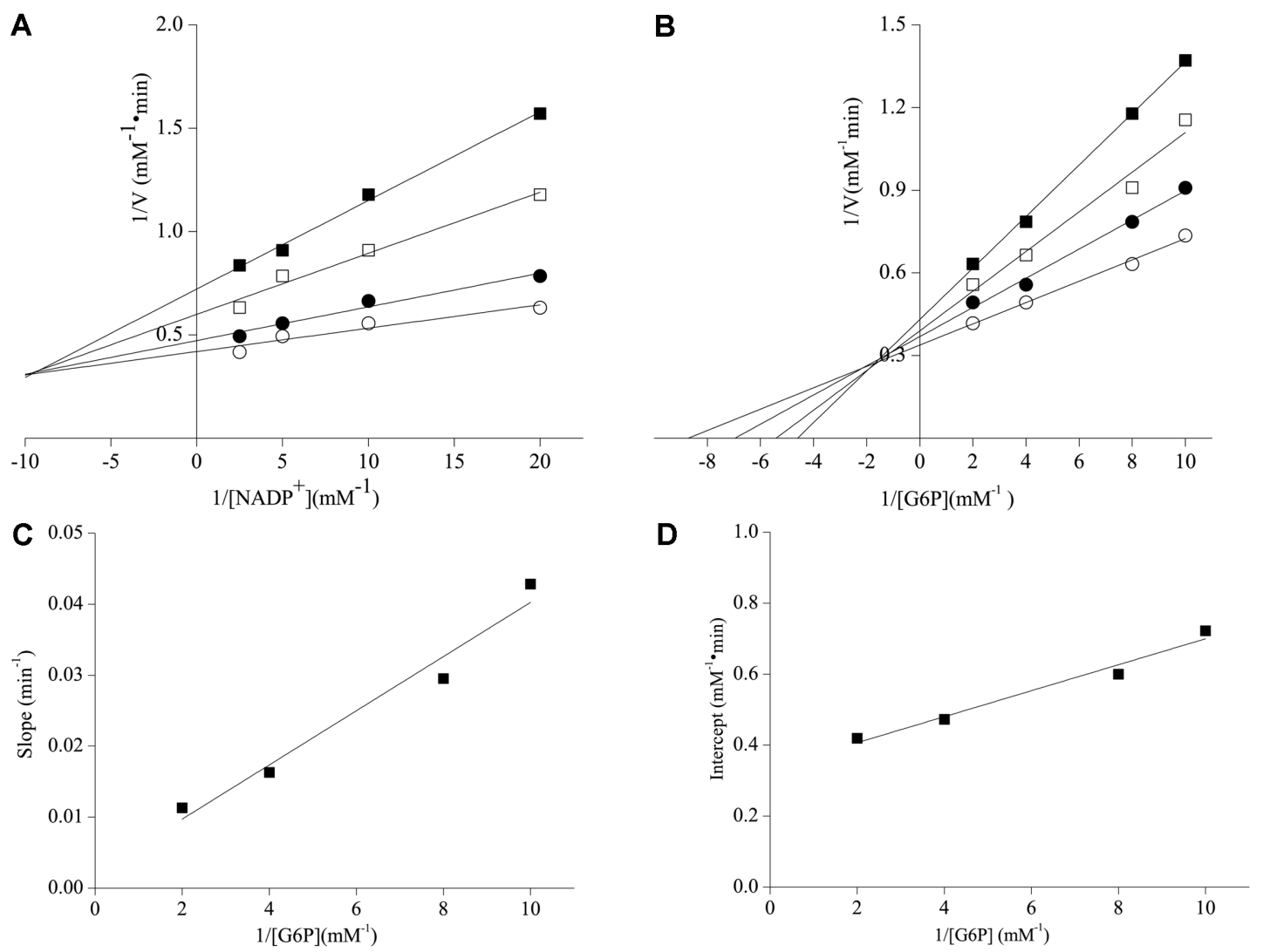

Fig. 4. Initial velocity analyses for $\mathrm{NADP}^{+}$-dependent AoG6PDH.

A: Primary double reciprocal plot of $1 / \mathrm{V}$ versus $1 /\left[\mathrm{NADP}^{+}\right]$at several fixed concentrations of G6P, $0.100 \mathrm{mM}$ G6P

$0.125 \mathrm{mM} \mathrm{G6P}(\square)$ $0.250 \mathrm{mM}$ G6P $(\bigcirc), 0.500 \mathrm{mM}$ G6P $(\bigcirc)$, and the corresponding $\mathrm{R}^{2}$ value of each plot was $0.99,0.96,0.95$ and 0.90 respectively. B: Primary double reciprocal plot of 1/V versus 1/[G6P] at several fixed concentrations of $\mathrm{NADP}^{+}, 0.050 \mathrm{mM} \mathrm{NADP}^{+}(\boldsymbol{\square}), 0.100 \mathrm{mM} \mathrm{NADP}^{+}(\square), 0.200 \mathrm{mM} \mathrm{NADP}^{+}$ (-), $0.400 \mathrm{mM} \mathrm{NADP}^{+}(\bigcirc)$, and the corresponding $\mathrm{R}^{2}$ value of each plot was $0.99,0.95,0.98$ and 0.99 respectively. C: Secondary plot of slopes of lines from primary plot A versus $1 /[\mathrm{G} 6 \mathrm{P}]$, and the $\mathrm{R}^{2}$ was 0.95 . D: Secondary plot of intercepts of lines from primary plot $A$ versus $1 /[\mathrm{G} 6 \mathrm{P}]$, and the $R^{2}$ value was 0.96 . The data represent the averages of duplicate runs. 
G6PDHs $\left(30-92^{\circ} \mathrm{C}\right)$ [21]. The G6PDH had an approximately $60-80 \%$ of its maximum activity at $35-45^{\circ} \mathrm{C}$, but only $\sim 2$ and $\sim 30 \%$ of its maximum activity at $60^{\circ} \mathrm{C}$ and $20^{\circ} \mathrm{C}$ were gauged, respectively.

The thermostability of G6PDH was observed and showed that about $60 \%$ of activity was maintained under a condition of $40^{\circ} \mathrm{C}$ after incubation for $30 \mathrm{~min}$ with a halflife following first-order kinetics of $33.3 \mathrm{~min}$ (Fig. 3C). However, when the temperature was above $50^{\circ} \mathrm{C}$, the activity of G6PDH decreased rapidly and the half-life of was only $16.3 \mathrm{~min}$ and $13.6 \mathrm{~min}$ at $50^{\circ} \mathrm{C}$ and $55^{\circ} \mathrm{C}$, respectively.

The effects of different metal ions on G6PDH activity were also investigated. Compared to the control reaction without metal ions, $\mathrm{Zn}^{2+}, \mathrm{Cu}^{2+}, \mathrm{Mg}^{2+}$ notably enhanced its activity $\left(273 \%, 237 \%\right.$, and $192 \%$, respectively). $\mathrm{Ca}^{2+}$ and $\mathrm{Fe}^{3+}$ had no obvious effect $(109 \%$ and $98 \%) . \mathrm{K}^{+}$and $\mathrm{Mn}^{2+}$ presented an inhibition effect ( $84 \%$ and $28 \%$ ).

\section{Kinetic Properties of Recombinant AoG6PDH}

To elucidate the kinetic mechanism, the recombinant AoG6PDH was used for two substrate, steady-state kinetic analysis. Initial velocity experiments provided clues to differentiate sequential from ping-pong mechanism. The initial velocity studies were performed by measuring G6PDH activity varying the concentrations of G6P and $\mathrm{NADP}^{+}$at several fixed concentrations. The results were represented on Lineweaver-Burk plots. The corresponding set of the double reciprocal plots were linear and converged to the left of the $\mathrm{Y}$-axis with $\mathrm{R}^{2}$ values of 0.90 to 0.99 respectively (Figs. 4A and 4B). Accordingly, the pingpong mechanism was excluded and the kinetic mechanism of the enzyme was deemed to be sequential. To determine whether it was a steady-state ordered or a rapid equilibrium random BiBi mechanism, the secondary plots of these slopes and intercepts versus the reciprocal of fixed substrate concentrations were implemented. A set of straight lines was obtained with values of 0.96 and 0.99 respectively (Figs. 4C and 4D), which supported a sequential mechanism for the AoG6PDH.

Product inhibition studies were performed to ascertain the substrate binding profile and product releasing profile. Because of the instability of the 6-phosphoglucono- $\delta$-lactone (6PGDL), only NADPH inhibition experiments were performed. The double reciprocal plots of initial velocity versus several fixed concentrations of NADPH yielded a series of lines intersecting with $\mathrm{R}^{2}$ values of 0.96 to 0.99 respectively. These results indicated that NADPH exhibited a competitive inhibition with respect to $\mathrm{NADP}^{+}$(Fig. 5A) and a linear mixed inhibition with respect to G6P (Fig. 5B). The inhibition pattern coincided with the steady-state ordered $\mathrm{BiBi}$ mechanism, where $\mathrm{NADP}^{+}$is the first substrate bound to the enzyme and NADPH is the second product released from the enzyme.

A general description of two substrate ordered reactions was given by Eq. (1), where A and B represented the first bonding substrate $\mathrm{NADP}^{+}$and the second G6P, respectively. Secondary plots of intercepts and slopes of lines from the
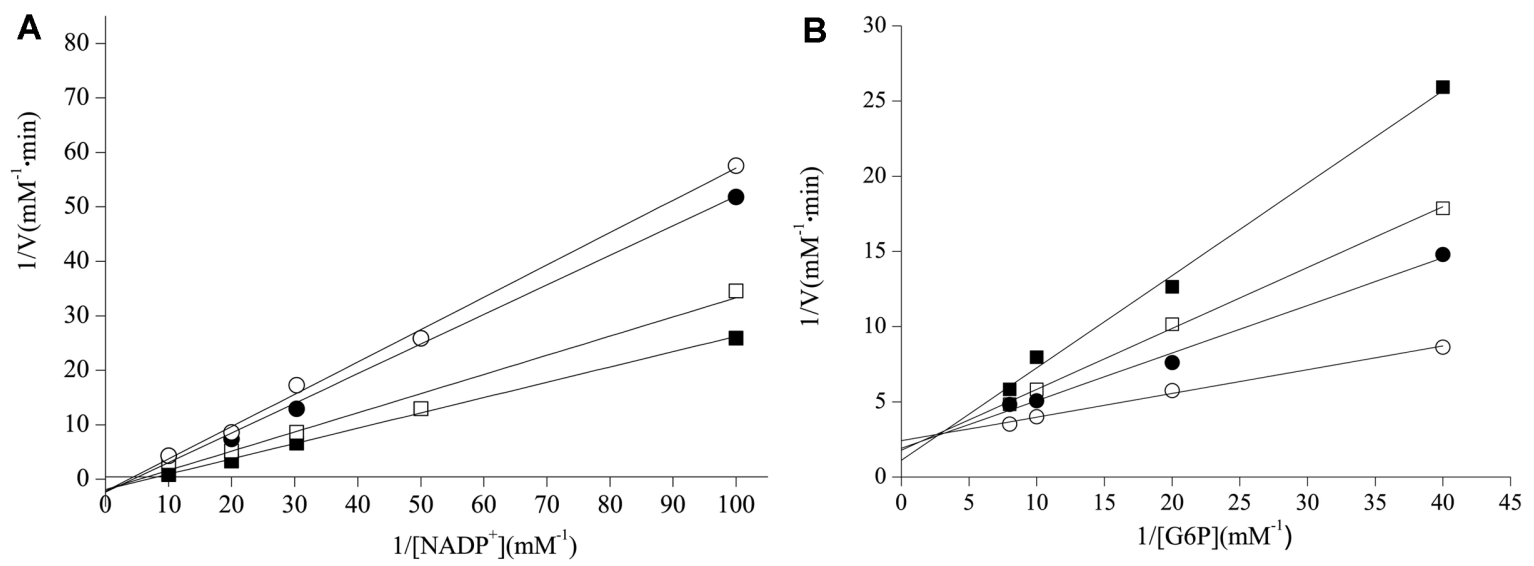

Fig. 5. Double-reciprocal plot of inhibition of G6PDH by several fixed concentrations of NADPH, with respect to NADP ${ }^{+}(\mathbf{A})$ and G6P (B).

口: $0.000 \mathrm{mM}$ NADPH, $\square: 0.025 \mathrm{mM}$ NADPH, $0: 0.050 \mathrm{mM} \mathrm{NADPH}, \bigcirc: 0.075 \mathrm{mM}$ NADPH respectively. The corresponding $R^{2}$ value of each plot in A was $0.99(\mathbf{\square}), 0.97(\square), 0.99(\bigcirc)$ and $0.99(\bigcirc)$, respectively. $R^{2}$ value of each plot in B was $0.99(\mathbf{\square}), 0.99(\square), 0.98(\bullet)$ and $0.99(\bigcirc)$ respectively. The data represent the averages of duplicate runs. 
Table 1. Kinetic parameters of G6PDH from A. oryzae.

\begin{tabular}{cccccc}
\hline Substrate & $K_{\mathrm{m}}(\mu \mathrm{M})$ & $K_{\mathrm{i}}(\mu \mathrm{M})$ & $\mathrm{V}_{\max }\left(\mathrm{u} \cdot \mathrm{ml}^{-1}\right)$ & $k_{\text {cat }}\left(\mathrm{s}^{-1}\right)$ & $k_{\text {cat }} / K_{\mathrm{m}}\left(\mathrm{s}^{-1} \cdot \mu \mathrm{M}^{-1}\right)$ \\
\hline $\mathrm{G} 6 \mathrm{P}$ & 109.7 & - & 3.0 & 1000.0 & 9.1 \\
$\mathrm{NADP}^{+}$ & 6.3 & 16.7 & 3.0 & 1000.0 & 158.7 \\
\hline
\end{tabular}

-: not detected

main plot with 1/ [G6P] as the variable can be utilized to estimate the kinetic constants (Fig. 4B). The obtained kinetic constants were listed in Table 1.

\section{Discussion}

Regulation of intracellular cofactor content and its regeneration is both of academic and application relevance for desired metabolite production in cellulolytic fungi using $\mathrm{CBP}$ technologies. To characterize the rate-limiting catalytic step in the PP pathway by G6PDH in A. oryzae CICC2012, which was one of the best potential targets for enhancing cofactor generation, the enzyme was heterogeneously expressed and functionally characterized.

According to the specificity of coenzyme, G6PDH can be divided into three categories: $\mathrm{NADP}^{+}$-strictly specific, $\mathrm{NADP}^{+}$-preferred and $\mathrm{NAD}^{+}$-preferred dual coenzyme specificity. Most G6PDH reported are strictly $\mathrm{NADP}^{+}$dependent or $\mathrm{NADP}^{+}$-preferred enzymes, a few can also utilize $\mathrm{NAD}^{+}$. The recombinant AoG6PDH did not show any activity when $\mathrm{NAD}^{+}$was used as the coenzyme, exhibiting strictly $\mathrm{NADP}^{+}$-dependent specificity. G6PDHs from other Aspergillus species, such as A. niger [27], A. nidulans [27], A. parasiticus [28] and A. aculeatus [29], also exhibited strict specificity towards $\mathrm{NADP}^{+}$. In all $\mathrm{NADP}^{+}$preferred G6PDHs, the conserved Arg residue was revealed and identified as a determinant in the $\mathrm{NADP}^{+}$specificity [21]. The conserved Arg residue binds tightly with the negatively charged phosphate group of $\mathrm{NADP}^{+}$via forming an electrostatic interaction [21]. The corresponding Arg residue was assessed in AoG6PDH, while, in some dual coenzyme specific enzymes the corresponding Arg residue still existed [30]. According to the crystallographic structure of dual coenzyme specific LmG6PDH, the dual coenzyme specificity was also associated with key residues surrounding conserved Arg residue and oligomeric states switching between binary and ternary enzyme complexes [15, 23].

Two substrate, steady-state kinetic analyses were used for elucidating the kinetic mechanism of the $\mathrm{NADP}^{+}$dependent AoG6PDH. The double reciprocal plots of the initial velocity have a linear intersecting pattern, which excludes the ping-pong mechanism. Since NADPH is a competitive inhibitor to $\mathrm{NADP}^{+}$and a mixed inhibitor to $\mathrm{G} 6 \mathrm{P}$, an ordered BiBi mechanism fits our data best, in which $\mathrm{NADP}^{+}$is the first substrate bound to the enzyme, and NADPH is the second product dissociated from the enzyme complex.

A similar mechanism has been proposed for G6PDHs

Table 2. Properties of G6PDH from various organisms.

\begin{tabular}{|c|c|c|c|c|c|c|c|c|}
\hline Organism & $\begin{array}{c}\text { Subunit } \\
\text { mol mass } \\
(\mathrm{kDa})\end{array}$ & $\begin{array}{c}\text { Native } \\
\text { mol mass } \\
(\mathrm{kDa})\end{array}$ & $k_{\text {cat }}\left(\mathrm{s}^{-1}\right)$ & $\begin{array}{c}K_{\mathrm{m}} \text { for G6P } \\
\quad(\mu \mathrm{M})\end{array}$ & $\begin{array}{c}k_{\text {cat }} / K_{\mathrm{m}} \text { for G6P } \\
\left(\mathrm{s}^{-1} \cdot \mu \mathrm{M}^{-1}\right)\end{array}$ & $\begin{array}{l}K_{\mathrm{m}} \text { for } \mathrm{NADP}^{+} \\
(\mu \mathrm{M})\end{array}$ & $\begin{array}{c}k_{\text {cat }} / K_{\mathrm{m}} \text { for NADP } \\
\left(\mathrm{s}^{-1} \cdot \mu \mathrm{M}^{-1}\right)\end{array}$ & $\begin{array}{c}\text { Optimal } \\
\text { pH }\end{array}$ \\
\hline A. oryzae (this work) & 58.8 & 118 & 1000 & 109.7 & 9.1 & 6.3 & 158.7 & 7.5 \\
\hline A. niger[27] & $57-60$ & 160 & ND & 153 & $\mathrm{ND}^{*}$ & 26 & ND & 9.0 \\
\hline A. nidulms [27] & $53-55$ & 180 & ND & 92 & $\mathrm{ND}^{*}$ & 30 & ND & 9.0 \\
\hline A. aculeatus [29] & 52 & 105 & 83 & 75 & 1.1 & 6 & 14 & 7.5 \\
\hline Y. lipolytica [21] & 55 & 219 & 182.7 & 264.9 & 0.58 & 33.3 & 5.49 & 8.5 \\
\hline T. maritima [38] & 60 & 95 & 35000 & 200 & 175 & 40 & 890 & 7.4 \\
\hline P. aeruginosa [39] & 55.6 & 250 or 500 & 540 & 498.7 & 2.38 & 56.7 & 9.52 & 8.8 \\
\hline E. coli DH5a [41] & 55 & 117 & 32.5 & 224 & 0.15 & 127 & 0.26 & 8.0 \\
\hline T. cruzi [42] & 62 & 158 & 62 & 77 & 0.8 & 16 & 3.2 & 7.5 \\
\hline T. crassiceps [43] & 61 & 134 & 34 & 14 & 2.43 & 1.3 & 26.1 & 7.8 \\
\hline Human [40] & 57 & 220 & 275 & 52 & 5.31 & 7.07 & 39.7 & 8.0 \\
\hline
\end{tabular}

*ND: not detected 
from human, pig and rat liver [31], human placental [32], human erythrocyte [26], bovine lens [33], Corynebacterium glutamicum [34], and Schizosaccharomyces pombe [35]. For G6PDH from lamb kidney cortex, an ordered mechanism has been deduced from inhibition studies, but with G6P as the first substrate bound to the enzyme [24]. In the kinetic mechanism studies of G6PDHs from some other sources such as fungi and mammals, rabbit erythrocytes, rat breast, and bovine adrenals, it was shown that the enzymes follow a random BiBi mechanism [27]. The enzyme purified from L. mesenterroides can use both $\mathrm{NAD}^{+}$and $\mathrm{NADP}^{+}$as substrates. When $\mathrm{NAD}^{+}$was the substrate, the enzyme obeys a random $\mathrm{BiBi}$, otherwise it obeys an ordered $\mathrm{BiBi}$ mechanism [36]. The kinetic studies on recombinant human G6PD suggested that the enzyme follows either random or ordered mechanisms [37].

The $K_{\mathrm{m}}$ values of AoG6PDH were calculated as 109.7 and $6.3 \mathrm{mM}$ for G6P and $\mathrm{NADP}^{+}$, respectively. The $K_{\mathrm{m}}$ value for $\mathrm{NADP}^{+}$was lower than that for G6P, suggesting the higher affinity of AoG6PDH to NADP ${ }^{+}$when compared with G6P, similar to those in other studies (Table 2). The catalytic efficiency $\left(k_{\text {cat }} / K_{\mathrm{m}}\right)$ for G6P and $\mathrm{NADP}^{+}$was 9.1 and $158.7 \mathrm{~s}^{-1} \cdot \mu \mathrm{M}^{-1}$, respectively, suggesting that the enzyme was more efficient with $\mathrm{NADP}^{+}$as the substrate. Table 2 displays the kinetic characteristics of purified G6PDHs from various organisms. Compared to these enzymes, except T. maritime G6PDH [38], AoG6PDH has both higher $k_{\text {cat }}$ and catalytic efficiencies $\left(k_{\text {cat }} / K_{\mathrm{m}}\right)$ with respect to G6P and $\mathrm{NADP}^{+}$. Its $k_{\text {cat }}$ is 11-fold higher than the Aspergillus enzyme (A. aculeatus $\mathrm{G} 6 \mathrm{PDH}$ ) [29] and 85\% higher than $P$. aeruginosa G6PDH [39]. Its catalytic efficiency with respect to $\mathrm{NADP}^{+}$ was 7-fold higher than that of the human G6PDH [40] and 5 -fold higher than that of any of the other G6PDHs.

In conclusion, putative G6PDH from industrial A. oryzae CICC2012 has now been identified and characterized by heterogeneous expression and purification for the first time. The recombined protein exhibited strictly $\mathrm{NADP}^{+}$-dependent activity, which discriminated the complex catalytic mechanism. The established kinetic model could be applied in further regulation of the pentose phosphate pathway and intracellular content of $\mathrm{NADPH} / \mathrm{NADP}^{+}$for improving the xylose utilization and yields of valued metabolites.

\section{Acknowledgments}

This work was supported by grants from the National Natural Science Foundation of China (No. 21476093 and 21706084), the Natural Science Foundation of Fujian Province
(No. 2018J01010) and the Scientific Research Funds of Huaqiao University (16BS103).

\section{Conflict of Interest}

The authors have no financial conflicts of interest to declare.

\section{References}

1. Olson DG, McBride JE, Shaw AJ, Lynd LR. 2012. Recent progress in consolidated bioprocessing. Curr. Opin. Biotechnol. 23: 396-405.

2. Bourdichon F, Casaregola S, Farrokh C, Frisvad JC, Gerds ML, Hammes WP, et al. 2012. Food fermentations: microorganisms with technological beneficial use. Int. J. Food Microbiol. 154: 87-97.

3. Szabo OE, Csiszar E, Koczka B, Kiss K. 2015. Ultrasonically assisted single stage and multiple extraction of enzymes produced by Aspergillus oryzae on a lignocellulosic substrate with solid-state fermentation. Biomass Bioenergy 75: 161-169.

4. Lin H, Wang Q, Shen Q, Ma J, Fu J, Zhao Y. 2014. Engineering Aspergillus oryzae A-4 through the chromosomal insertion of foreign cellulase expression cassette to improve conversion of cellulosic biomass into lipids. PLoS One 9: e108442.

5. El-Ghonemy DH, Ali TH, El-Bondkly AM, Moharam Mel S, Talkhan FN. 2014. Improvement of Aspergillus oryzae NRRL 3484 by mutagenesis and optimization of culture conditions in solid-state fermentation for the hyper-production of extracellular cellulase. Antonie Van Leeuwenhoek 106: 853-864.

6. Hirayama K, Watanabe H, Tokuda G, Kitamoto K, Arioka M. 2010. Purification and characterization of termite endogenous beta-1,4-endoglucanases produced in Aspergillus oryzae. Biosci. Biotechnol. Biochem. 74: 1680-1686.

7. Maas RH, Springer J, Eggink G, Weusthuis RA. 2008. Xylose metabolism in the fungus Rhizopus oryzae: effect of growth and respiration on L(+)-lactic acid production. J. Ind. Microbiol. Biotechnol. 35: 569-578.

8. Xu Q, Li S, Fu Y, Tai C, Huang H. 2010. Two-stage utilization of corn straw by Rhizopus oryzae for fumaric acid production. Bioresour. Technol. 101: 6262-6264.

9. Tran LH, Kitamoto N, Kawai K, Takamizawa K, Suzuki T. 2004. Cloning and expression of a NAD ${ }^{+}$-dependent xylitol dehydrogenase gene $(x d h A)$ of Aspergillus oryzae. J. Biosci. Bioeng. 97: 419-422.

10. Runquist D, Hahn-Hagerdal B, Bettiga M. 2010. Increased ethanol productivity in xylose-utilizing Saccharomyces cerevisiae via a randomly mutagenized xylose reductase. Appl. Environ. Microbiol. 76: 7796-7802. 
11. Chin JW, Cirino PC. 2011. Improved NADPH supply for xylitol production by engineered Escherichia coli with glycolytic mutations. Biotechnol. Prog. 27: 333-341.

12. Ahmad I, Shim WY, Kim JH. 2013. Enhancement of xylitol production in glycerol kinase disrupted Candida tropicalis by co-expression of three genes involved in glycerol metabolic pathway. Bioprocess Biosyst. Eng. 36: 1279-1284.

13. Oh EJ, Ha SJ, Rin Kim S, Lee WH, Galazka JM, Cate JH, et al. 2013. Enhanced xylitol production through simultaneous co-utilization of cellobiose and xylose by engineered Saccharomyces cerevisiae. Metab. Eng. 15: 226-234.

14. Au SW, Gover S, Lam VM, Adams MJ. 2000. Human glucose-6-phosphate dehydrogenase: the crystal structure reveals a structural $\mathrm{NADP}^{+}$molecule and provides insights into enzyme deficiency. Structure 8: 293-303.

15. Ranzani AT, Cordeiro AT. 2017. Mutations in the tetramer interface of human glucose-6-phosphate dehydrogenase reveals kinetic differences between oligomeric states. FEBS Lett. 591: 1278-1284.

16. Temel Y, Kocyigit UM. 2017. Purification of glucose-6phosphate dehydrogenase from rat (Rattus norvegicus) erythrocytes and inhibition effects of some metal ions on enzyme activity. J. Biochem. Mol. Toxicol. 31(9).

17. Du Y, Xie G, Yang C, Fang B, Chen H. 2014. Construction of brewing-wine Aspergillus oryzae $\mathrm{pyrG}^{-}$mutant by pyrG gene deletion and its application in homology transformation. Acta. Biochim. Biophys. Sin. (Shanghai) 46: 477-483.

18. Waterhouse A, Bertoni M, Bienert S, Studer G, Tauriello G, Gumienny R, et al. 2018. SWISS-MODEL: homology modelling of protein structures and complexes. Nucleic Acids Res. 46: W296-W303.

19. Bradford MM. 2015. A rapid method for quantitation of microgram quantities of protein utilizing the principle of protein-dye binding. Anal. Biochem. 72: 248-254.

20. Kruger NJ. 2002. The Bradford method for protein quantitation, pp. 15-21. The protein protocols handbook, Springer,

21. Bian M, Li S, Wei H, Huang S, Zhou F, Zhu Y, et al. 2018. Heteroexpression and biochemical characterization of a glucose-6-phosphate dehydrogenase from oleaginous yeast Yarrowia lipolytica. Protein Expr. Purif. 148: 1-8.

22. Purich DL. 2010. Enzyme kinetics: catalysis and control: a reference of theory and best-practice methods, pp. 335-338. $1^{\text {st }}$ Ed. Elsevier.

23. Naylor CE, Gover S, Basak AK, Cosgrove MS, Levy HR, Adams MJ. 2001. $\mathrm{NADP}^{+}$and $\mathrm{NAD}^{+}$binding to the dual coenzyme specific enzyme Leuconostoc mesenteroides glucose 6-phosphate dehydrogenase: different interdomain hinge angles are seen in different binary and ternary complexes. Acta crystallogr. D. Biol. Crystallogr. 57: 635-648.

24. Ulusu NN, Tandogan B, Tezcan FE. 2005. Kinetic properties of glucose-6-phosphate dehydrogenase from lamb kidney cortex. Biochimie 87: 187-190.
25. Verma A, Suthar MK, Doharey PK, Gupta S, Yadav S, Chauhan PMS, et al. 2013. Molecular cloning and characterization of glucose-6-phosphate dehydrogenase from Brugia malayi. Parasitology 140: 897-906.

26. Adediran SA. 1991. Kinetic properties of normal human erythrocyte glucose-6-phosphate dehydrogenase dimers. Biochimie. 73: 1211-1218.

27. Wennekes LM, Goosen T, van den Broek PJ, van den Broek HW. 1993. Purification and characterization of glucose-6-phosphate dehydrogenase from Aspergillus niger and Aspergillus nidulans. J. Gen. Microbiol. 139: 2793-2800.

28. Jr NW, Jr DR. 1984. Purification and characterization of glucose-6-phosphate dehydrogenase from Aspergillus parasiticus. Arch. Biochem. Biophys. 228: 113-119.

29. Omodele Ibraheem IOAaAA. 2005. Purification and properties of glucose 6-phosphate dehydrogenase from Aspergillus aculeatus. J. Biochem. Mol. Biol. 38: 584-590.

30. Rowland P, Basak AK, Gover S, Levy HR, Adams MJ. 1994. The three-dimensional structure of glucose 6-phosphate dehydrogenase from Leuconostoc mesenteroides refined at $2.0 \AA$ resolution. Structure 2: 1073-1087.

31. Shreve DS, Levy HR. 1980. Kinetic mechanism of glucose-6phosphate dehydrogenase from the lactating rat mammary gland. Implications for regulation. J. Biol. Chem. 255: 26702677.

32. Aksoy Y, Ogüs IH, Oauzer N. 2001. Purification and some properties of human placental glucose-6-phosphate dehydrogenase. Protein Expr. Purif. 21: 286-292.

33. Ulusu NN, Kus MS, Acan NL, Tezcan EF. 1999. A rapid method for the purification of glucose-6-phosphate dehydrogenase from bovine lens. Int. J. Biochem. Cell Biol. 31: 787-796.

34. Moritz B, Striegel K, Graaf AA, De, Sahm H. 2010. Kinetic properties of the glucose-6-phosphate and 6-phosphogluconate dehydrogenases from Corynebacterium glutamicum and their application for predicting pentose phosphate pathway flux in vivo. FEBS J. 267: 3442-3452.

35. Tsai CS, Chen Q. 1998. Purification and kinetic characterization of hexokinase and glucose-6-phosphate dehydrogenase from Schizosaccharomyces pombe. Biochem. Cell Biol. 76: 107-113.

36. Levy HR, Christoff M, Ingulli J, Ho EML. 1983. Glucose-6phosphate dehydrogenase from Leuconostoc mesenteroides: Revised kinetic mechanism and kinetics of ATP inhibition. Arch. Biochem. Biophys. 222: 473-488.

37. Wang XT, Au SW, Lam VM, Engel PC. 2002. Recombinant human glucose-6-phosphate dehydrogenase. Evidence for a rapid-equilibrium random-order mechanism. Eur. J. Biochem. 269: 3417-3424.

38. Hansen T, Schlichting B, Schonheit P. 2002. Glucose-6phosphate dehydrogenase from the hyperthermophilic bacterium Thermotoga maritima: expression of the g6pd gene and characterization of an extremely thermophilic enzyme. FEMS Microbiol. Lett. 216: 249-253. 
39. Acero-Navarro KE, Jimenez-Ramirez M, Villalobos MA, Vargas-Martinez R, Perales-Vela HV, Velasco-Garcia R. 2018. Cloning, overexpression, and purification of glucose-6phosphate dehydrogenase of Pseudomonas aeruginosa. Protein Expr. Purif. 142: 53-61.

40. Wang XT, Lam VM, Engel PC. 2005. Marked decrease in specific activity contributes to disease phenotype in two human glucose 6-phosphate dehydrogenase mutants, G6PD(Union) and G6PD(Andalus). Hum. Mutat. 26: 284.

41. Schuurmann J, Quehl P, Lindhorst F, Lang K, Jose J. 2017. Autodisplay of glucose-6-phosphate dehydrogenase for redox cofactor regeneration at the cell surface. Biotechnol. Bioeng. 114: 1658-1669.

42. Ortiz C, Moraca F, Medeiros A, Botta M, Hamilton N, Comini MA. 2016. Binding mode and selectivity of steroids towards glucose-6-phosphate dehydrogenase from the pathogen Trypanosoma cruzi. Molecules 21: 368.

43. Rendón JL, del Arenal IP, Guevara-Flores A, MendozaHernández G, Pardo JP. 2008. Glucose 6-phosphate dehydrogenase from larval Taenia crassiceps (cysticerci): purification and properties. Parasitol. Res. 102: 1351-1357. 